\title{
Parkinson's disease: clinical features and diagnosis
}

\author{
J Jankovic
}

Correspondence to:

Professor J Jankovic, Department of Neurology,

Parkinson's Disease Center and Movement Disorders Clinic,

Baylor College of Medicine, 6550 Fannin, Suite 1801 , Houston, Texas 77030-3498,

USA; josephj@bcm.tmc.edu

Received 26 July 2007

Revised 3 September 2007

Accepted 4 September 2007

\begin{abstract}
Objective: Parkinson's disease (PD) is a progressive neurological disorder characterised by a large number of motor and non-motor features that can impact on function to a variable degree. This review describes the clinical characteristics of PD with emphasis on those features that differentiate the disease from other parkinsonian disorders.
\end{abstract}

Methods: A MedLine search was performed to identify studies that assess the clinical characteristics of PD. Search terms included "Parkinson's disease", "diagnosis" and "signs and symptoms".

Results: Because there is no definitive test for the diagnosis of PD, the disease must be diagnosed based on clinical criteria. Rest tremor, bradykinesia, rigidity and loss of postural reflexes are generally considered the cardinal signs of PD. The presence and specific presentation of these features are used to differentiate PD from related parkinsonian disorders. Other clinical features include secondary motor symptoms (eg, hypomimia, dysarthria, dysphagia, sialorrhoea, micrographia, shuffling gait, festination, freezing, dystonia, glabellar reflexes), nonmotor symptoms (eg, autonomic dysfunction, cognitive/ neurobehavioral abnormalities, sleep disorders and sensory abnormalities such as anosmia, paresthesias and pain). Absence of rest tremor, early occurrence of gait difficulty, postural instability, dementia, hallucinations, and the presence of dysautonomia, ophthalmoparesis, ataxia and other atypical features, coupled with poor or no response to levodopa, suggest diagnoses other than PD. Conclusions: A thorough understanding of the broad spectrum of clinical manifestations of $P D$ is essential to the proper diagnosis of the disease. Genetic mutations or variants, neuroimaging abnormalities and other tests are potential biomarkers that may improve diagnosis and allow the identification of persons at risk.

In his 1817 "An essay on the shaking palsy", James Parkinson first described the clinical syndrome that was later to bear his name. ${ }^{1}$ He identified six cases, three of whom he personally examined; three he observed on the streets of London. Previously referred to as "paralysis agitans", Charcot later in the 19th century gave credit to Parkinson by referring to the disease as "maladie de Parkinson" or Parkinson's disease (PD). Charcot also recognised non-tremulous forms of $\mathrm{PD}$ and correctly pointed out that slowness of movement should be distinguished from weakness or "lessened muscular power", a term originally used by Parkinson. ${ }^{2}$ More than 100 years passed (1919) after the original description by Parkinson before it was recognised that patients with PD lose cells in the substantia nigra, and 140 years passed (1957) before dopamine was discovered as a putative neurotransmitter by Carlsson and colleagues in Lund, Sweden. ${ }^{3}$ The discovery by Ehringer and Hornykiewicz in
$1960^{3}$ that dopamine concentrations are markedly decreased in the striatum of patients with PD paved the way for the first trials of levodopa in $\mathrm{PD}$ patients the following year ${ }^{5}$ and subsequent award of the Nobel Prize in Medicine to Carlsson in 2000. The ability of injected levodopa to improve akinesia in patients with PD was first demonstrated in 1961 and was followed by the development of oral levodopa later in the decade. ${ }^{67}$ More recently, genetic mutations, abnormal handling of misfolded proteins by the ubiquitin-proteasome and the autophagy-lysosomal systems, increased oxidative stress, mitochondrial dysfunction, inflammation and other pathogenic mechanisms have been identified as contributing factors in the death of dopaminergic and non-dopaminergic cells in the brains of patients with $\mathrm{PD} .^{89}$ It is beyond the scope of this review to discuss the various pathogenic mechanisms, management or treatment related complications that have been the subjects of recent reviews and volumes. ${ }^{10}{ }^{11}$ This article focuses on the clinical features of $\mathrm{PD}$ and the differentiation of the disease from other parkinsonian disorders.

\section{CLINICAL FEATURES}

There are four cardinal features of PD that can be grouped under the acronym TRAP: Tremor at rest, Rigidity, Akinesia (or bradykinesia) and Postural instability. In addition, flexed posture and freezing (motor blocks) have been included among classic features of parkinsonism, with $\mathrm{PD}$ as the most common form. Because of the diverse profiles and lifestyles of those affected by PD, motor and nonmotor impairments should be evaluated in the context of each patient's needs and goals. ${ }^{12}$

A number of rating scales are used for the evaluation of motor impairment and disability in patients with $\mathrm{PD}$, but most of these scales have not been fully evaluated for validity and reliability. ${ }^{13}{ }^{14}$ The Hoehn and Yahr scale is commonly used to compare groups of patients and to provide gross assessment of disease progression, ranging from stage 0 (no signs of disease) to stage 5 (wheelchair bound or bedridden unless assisted). The Unified Parkinson's Disease Rating scale (UPDRS) is the most well established scale for assessing disability and impairment. ${ }^{13}{ }^{15}$ Studies making use of UPDRS to track the progression of $\mathrm{PD}$ suggest that the course of PD is not linear and that the rate of deterioration is variable and more rapid in the early phase of the disease and in patients with the postural instability gait difficulty (PIGD) of PD..$^{16-18}$ We prospectively followed-up 297 patients (181 men, 116 women) with clinically diagnosed PD for at least 3 years and, based on data from 1731 visits during an average of 6.36 years (range 3-17), we concluded that the annual rate of decline in the 
total UPDRS scores was 1.34 points when assessed during $\mathrm{ON}$ and 1.58 points when assessed during OFF. Patients who were older and had the PIGD form of PD at onset experienced more rapid disease progression than did those who were younger at onset and had the tremor dominant form of PD. Furthermore, the older group experienced significantly more progression in mentation, freezing and parts I and II UPDRS subscores. Handwriting was the only component of the UPDRS that did not significantly deteriorate during the observation period. On the other hand, many studies have shown that younger patients are at a higher risk for levodopa induced dyskinesias than older patients. ${ }^{19}$ In a prospective study of 145 clinic based patients followed-up for 1 year and of 124 community based patients followed-up for 4 years, the annual mean rate of deterioration in motor and disability scores ranged from $2.4 \%$ to $7.4 \% .^{20}$ The current UPDRS is undergoing revisions so that the revised scale will be more sensitive to detect small changes and it will integrate non-motor elements of $\mathrm{PD} .{ }^{15}$ Other types of rating scales include those that assess psychiatric manifestations (eg, depression $)^{21}$ and quality of life. ${ }^{14} 21$ The most frequent clinical features associated with $\mathrm{PD}$ are listed in table 1 and are discussed in the following sections.

\section{Bradykinesia}

Bradykinesia refers to slowness of movement and is the most characteristic clinical feature of $\mathrm{PD}$, although it may also be seen in other disorders, including depression. Bradykinesia is a hallmark of basal ganglia disorders, and it encompasses difficulties with planning, initiating and executing movement and with performing sequential and simultaneous tasks. ${ }^{22}$ The initial manifestation is often slowness in performing activities of daily living and slow movement and reaction times. ${ }^{23}{ }^{24}$ This may include difficulties with tasks requiring fine motor control (eg, buttoning, using utensils). Other manifestations of bradykinesia include loss of spontaneous movements and gesturing, drooling because of impaired swallowing, ${ }^{25}$ monotonic and hypophonic dysarthria, loss of facial expression (hypomimia) and decreased blinking, and reduced arm swing while walking. Given that bradykinesia is one of the most easily recognisable symptoms of $\mathrm{PD}$, it may become apparent before any formal neurological examination. Assessment of bradykinesia usually includes having patients perform rapid, repetitive, alternating movements of the hand (finger taps, hand grips, hand pronation-supination) and heel taps and observing not only slowness but also decrementing amplitude.

In common with other parkinsonian symptoms, bradykinesia is dependent on the emotional state of the patient. For example, immobile patients who become excited may be able to make quick movements such as catching a ball (or may be able to suddenly run if someone screams "fire"). This phenomenon (kinesia paradoxica) suggests that patients with PD have intact motor programmes but have difficulties accessing them without an external trigger, such as a loud noise, marching music or a visual cue requiring them to step over an obstacle.

Although the pathophysiology of bradykinesia has not been well delineated, it is the cardinal PD feature that appears to correlate best with degree of dopamine deficiency. ${ }^{26}$ This is supported by the observation of decreased neuronal density in the substantia nigra in elderly patients with parkinsonism regardless of $\mathrm{PD}$ diagnosis. ${ }^{27}$ In addition, positron emission tomography in patients with $\mathrm{PD}$ has demonstrated that the decreased ${ }^{18} \mathrm{~F}$-fluorodopa uptake in the striatum and accumbens-caudate complex is proportional to the degree of bradykinesia. ${ }^{28}$

It is hypothesised that bradykinesia is the result of a disruption in normal motor cortex activity mediated by reduced dopaminergic function. In a study assessing recordings from single cortical neurons in rats with haloperidol induced bradykinesia, a decrease in firing rates correlated with bradykinesia. ${ }^{29}$ Functional neuroimaging studies also suggest impairment in the recruitment of cortical and subcortical systems that regulate kinematic parameters of movement (eg, velocity). ${ }^{30}$ Conversely, recruitment of various premotor areas, such as those responsible for visuomotor control, is increased. ${ }^{30}$ Anatomically, the deficit appears to be localised in the putamen and globus pallidus, ${ }^{28}$ resulting in a reduction in the muscle force produced at the initiation of movement. Analysis of electromyographic recordings showed that patients with bradykinesia are unable to energise the appropriate muscles to provide enough force to initiate and maintain large fast movements. ${ }^{31}$ Because patients with PD have decreased electromyographic activity, $^{22}$ they need a series of multiple agonist bursts to accomplish larger movements.

\section{Tremor}

Rest tremor is the most common and easily recognised symptom of PD. Tremors are unilateral, occur at a frequency between 4 and $6 \mathrm{~Hz}$, and almost always are prominent in the distal part of an extremity. Hand tremors are described as supination-pronation ("pill-rolling") tremors that spread from one hand to the other. Rest tremor in patients with PD can also involve the lips, chin, jaw and legs but, unlike essential tremor, rarely involves the neck/head or voice. Thus a patient who presents with head tremor most likely has essential tremor, cervical dystonia, or both, rather than PD. Characteristically, rest tremor disappears with action and during sleep. Some patients also report an "internal" shaking that is not associated with a visible tremor. ${ }^{32}$ The tremor of PD is differentiated from that of essential tremor by a number of features (table 2).

Some patients with PD have a history of postural tremor, phenomenologically identical to essential tremor, for many years or decades before the onset of parkinsonian tremor or

Table 1 Parkinson's disease symptoms

\begin{tabular}{|c|c|}
\hline Motor symptoms & Non-motor symptoms \\
\hline Tremor, bradykinesia, rigidity, postural instability & $\begin{array}{l}\text { Cognitive impairment, bradyphrenia, tip-of-the-tongue (word finding) } \\
\text { phenomenon }\end{array}$ \\
\hline Hypomimia, dysarthria, dysphagia, sialorrhoea & $\begin{array}{l}\text { Depression, apathy, anhedonia, fatigue, other behavioural and } \\
\text { psychiatric problems }\end{array}$ \\
\hline $\begin{array}{l}\text { Decreased arm swing, shuffling gait, festination difficulty } \\
\text { arising from chair, turning in bed }\end{array}$ & $\begin{array}{l}\text { Sensory symptoms: anosmia, ageusia, pain (shoulder, back), } \\
\text { paresthesias }\end{array}$ \\
\hline $\begin{array}{l}\text { Micrographia, cutting food, feeding, hygiene, slow activities } \\
\text { of daily living }\end{array}$ & $\begin{array}{l}\text { Dysautonomia (orthostatic hypotension, constipation, urinary and } \\
\text { sexual dysfunction, abnormal sweating, seborrhoea), weight loss }\end{array}$ \\
\hline $\begin{array}{l}\text { Glabellar reflex, blepharospasm, dystonia, striatal deformity, } \\
\text { scoliosis, camptocormia }\end{array}$ & $\begin{array}{l}\text { Sleep disorders (REM behaviour disorder, vivid dreams, daytime } \\
\text { drowsiness, sleep fragmentation, restless legs syndrome) }\end{array}$ \\
\hline
\end{tabular}


Table 2 Features differentiating Parkinson's disease from essential tremor

\begin{tabular}{|c|c|c|}
\hline Feature & Parkinson's disease & Essential tremor \\
\hline Age at onset (y) & $55-75$ & $10-80$ \\
\hline Family history & $+/-$ & ++ \\
\hline Tremor frequency $(\mathrm{Hz})$ & $4-6$ & $5-10$ \\
\hline Tremor characteristics & Supination-pronation & Flexion-extension \\
\hline \multicolumn{3}{|l|}{ Influencing factors } \\
\hline Rest & Increases & Decreases \\
\hline Action & Decreases & Increases \\
\hline Mental concentration & Decreases & Increases \\
\hline Writing & Decreases (micrographia) & Increases (tremulous) \\
\hline Walking & Increases & Decreases \\
\hline Alcohol & - & Decreases \\
\hline Postural tremor & Re-emergent & Without latency \\
\hline Kinetic tremor & $+/-$ & Yes \\
\hline Limb tremor & Asymmetric & Symmetric \\
\hline Distribution other than limbs & Face, jaw, lips, chin & Head, voice \\
\hline Neuroimaging-dopaminergic system & Marked dopaminergic deficit & Mild dopaminergic deficit \\
\hline Mid-brain sonography & Marked hyper-echogenicity & Mild hyper-echogenicity \\
\hline Neuropathology & Nigrostriatal degeneration, Lewy bodies & $\begin{array}{l}\text { Mild cerebellar degeneration, Lewy bodies } \\
\text { in the substantia nigra, brainstem and } \\
\text { cerebellum some cases }\end{array}$ \\
\hline Treatment & $\begin{array}{l}\text { Anticholinergics, amantadine, } \\
\text { dopaminergic drugs, deep brain } \\
\text { stimulation }\end{array}$ & $\begin{array}{l}\text { Alcohol, beta-blockers, primidone, } \\
\text { topiramate, gabapentin, botulinum toxin, } \\
\text { deep brain stimulation }\end{array}$ \\
\hline
\end{tabular}

other PD related features. We and others have provided a growing body of evidence that indicates that essential tremor is a risk factor for PD. ${ }^{33}$

In addition to rest tremor, many patients with $\mathrm{PD}$ also have postural tremor that is more prominent and disabling than rest tremor and may be the first manifestation of the disease. ${ }^{34} 35$ Parkinson's related postural tremor ("re-emergent tremor") is differentiated from essential tremor in that the appearance of tremor is often delayed after the patient assumes an outstretched horizontal position. ${ }^{34}$ Because re-emergent tremor occurs at the same frequency as classical rest tremor and is responsive to dopaminergic therapy, it is likely that it represents a variant of the more typical rest tremor. There are several clues to the diagnosis of existent essential tremor when it coexists with PD, including longstanding history of action tremor, family history of tremor, head and voice tremor, and no latency when arms are outstretched in a horizontal position in front of the body, although some patients may also have a re-emergent tremor related to their $\mathrm{PD}$, tremulous handwriting and spiral, and improvement of the tremor with alcohol and beta-blockers.

The occurrence of rest tremor is variable among patients and during the course of the disease. In one study, Hughes and colleagues $^{36}$ reported that $69 \%$ of patients with PD had rest tremor at disease onset and that $75 \%$ had tremor during the course of their disease. Tremor was lost in $9 \%$ of patients late in the disease. Others have reported that a small proportion of patients $(11 \%)$ never have tremor, ${ }^{37}$ although a prospective study in patients with autopsy proven disease found that $100 \%$ of patients had tremor at some point. ${ }^{38}$ Clinical-pathological studies have demonstrated that patients with $\mathrm{PD}$ and prominent tremor have degeneration of a subgroup of midbrain (A8) neurons, whereas this area is spared in $\mathrm{PD}$ patients without tremor.

\section{Rigidity}

Rigidity is characterised by increased resistance, usually accompanied by the "cogwheel" phenomenon, particularly when associated with an underlying tremor, present throughout the range of passive movement of a limb (flexion, extension or rotation about a joint). It may occur proximally (eg, neck, shoulders, hips) and distally (eg, wrists, ankles). Reinforcing manoeuvres (eg, voluntary movements of the contralateral limb), known as the Froment's manoeuvre, ${ }^{39}$ usually increase rigidity and are particularly useful in detecting mild cases of rigidity.

Rigidity may be associated with pain, and painful shoulder is one of the most frequent initial manifestations of PD although it is commonly misdiagnosed as arthritis, bursitis or rotator cuff injury. ${ }^{40}{ }^{41} \mathrm{~A}$ prospective study of 6038 persons (mean age 68.5 years) with no evidence of dementia or parkinsonism at baseline found that the presence of stiffness, tremor and imbalance were each associated with increased risk for PD (hazard ratios 2.11, 2.09 and 3.47, respectively). ${ }^{42}$ Among this cohort, 56 new cases of PD were identified over a mean followup of 5.8 years.

\section{Postural deformities}

In addition, rigidity of the neck and trunk (axial rigidity) may occur, resulting in abnormal axial postures (eg, anterocollis, scoliosis). Postural deformities resulting in flexed neck and trunk posture and flexed elbows and knees are often associated with rigidity. However, flexed posture generally occurs late in the disease. Striatal limb deformities (eg, striatal hand, striatal toe) may also develop in some patients. Striatal hand is characterised by ulnar deviation of the hands, flexion of the metacarpophalangeal joints and extension of the proximal and flexion of the distal interphalangeal joints (fig 1A); striatal foot is characterised by extension or flexion (fig 1B) of the toes. ${ }^{43}{ }^{44}$ In one study, striatal toe (extension of the big toe) was reported in $21 \%$ of patients with clinically diagnosed PD. ${ }^{45}$ Patients with striatal deformities tend to be younger and to experience earlier onset of initial parkinsonian symptoms. ${ }^{44}$

Other skeletal abnormalities include extreme neck flexion ("dropped head" or "bent spine"), truncal flexion (camptocormia) and scoliosis. ${ }^{44-48}$ Camptocormia is characterised by extreme flexion of the thoracolumbar spine. The condition is 
exacerbated by walking and is relieved by sitting, lying in the supine position or by volitionally extending the trunk when the patient leans against a wall or a high walker or a table (fig 2AC). ${ }^{48}$ In addition to $\mathrm{PD}$, other causes of camptocormia include dystonia and extensor truncal myopathy. ${ }^{49} 50$ Another truncal deformity is the Pisa syndrome, which is characterised by a tilting of the trunk, particularly when sitting or standing. ${ }^{51}$

\section{Postural instability}

Postural instability due to loss of postural reflexes is generally a manifestation of the late stages of PD and usually occurs after the onset of other clinical features. The pull test, in which the patient is quickly pulled backward or forward by the shoulders, is used to assess the degree of retropulsion or propulsion, respectively. Taking more than two steps backwards or the absence of any postural response indicates an abnormal postural response. Postural instability (along with freezing of gait) is the most common cause of falls and contributes significantly to the risk of hip fractures. ${ }^{52}$ The long latency to the onset of falls differentiates PD from other neurodegenerative disorders, such as progressive supranuclear palsy (PSP) and multiple systems atrophy (MSA).$^{53}$ In one study, the average time from onset of symptoms to the first fall was 108 months in patients with PD compared with 16.8 and 42 months, respectively, in patients with PSP and MSA. ${ }^{2}$

Several other factors also influence the occurrence of postural instability in patients with PD. These include other parkinsonian symptoms, orthostatic hypotension, age related sensory changes and the ability to integrate visual, vestibular and proprioceptive sensory input (kinesthesia). ${ }^{54}{ }^{55}$ The fear of falling can further impair balance control in patients with PD. ${ }^{56}$ In one study, $38 \%$ of those evaluated experienced falls, and $13 \%$ fell more than once a week. ${ }^{57}$ As expected, the frequency of falls correlated with the severity of disease. ${ }^{57}$ Treatment (dopaminergic therapy, pallidotomy, deep brain stimulation) can improve some axial signs ${ }^{58}$ but usually does not robustly improve postural instability, measured by platform tilt and visual tilt. ${ }^{59}$ Targeting other nuclei for deep brain stimulation in addition to the subthalamic nucleus and globus pallidus, such as the zona incerta and pedunculopontine nucleus, is being

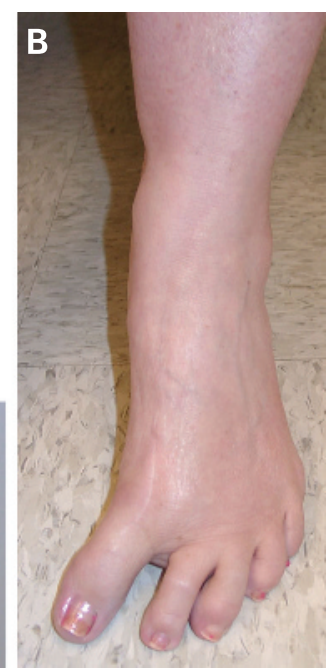

Figure 1 Striatal hand $(A)$ and foot $(B)$ deformity in a patient with typical Parkinson's disease. Patient consent has been received to publish this figure. explored as a potential surgical treatment of gait difficulties and postural stability. ${ }^{60}$

\section{Freezing}

Freezing, also referred to as motor blocks, is a form of akinesia (loss of movement) and is one of the most disabling symptoms of PD. ${ }^{61}$ Although freezing is a characteristic feature of PD, it does not occur universally. ${ }^{62}$ Based on responses by 6620 patients to a questionnaire sent to 12000 members of the German Parkinson Association, 47\% of patients reported freezing; it occurs more frequently in men than in women and less frequently in patients whose main symptom is tremor. ${ }^{63}$ Freezing most commonly affects the legs during walking, but the arms and eyelids can also be involved. ${ }^{64}$ It typically manifests as a sudden and transient (usually $<10 \mathrm{~s}$ ) inability to move. This may include hesitation when beginning to walk (start hesitation) or a sudden inability to move the feet during specific situations (eg, turning or walking through a narrow passage, crossing busy streets, approaching a destination). Freezing is associated with substantial social and clinical consequences for patients. In particular, it is a common cause of falls. ${ }^{62}$

Five subtypes of freezing have been described: start hesitation, turn hesitation, hesitation in tight quarters, destination hesitation and open space hesitation. ${ }^{65}$ Episodes are more severe in the OFF state and are mitigated by levodopa therapy. In addition, patients often develop tricks to overcome freezing attacks. This includes marching to command, stepping over
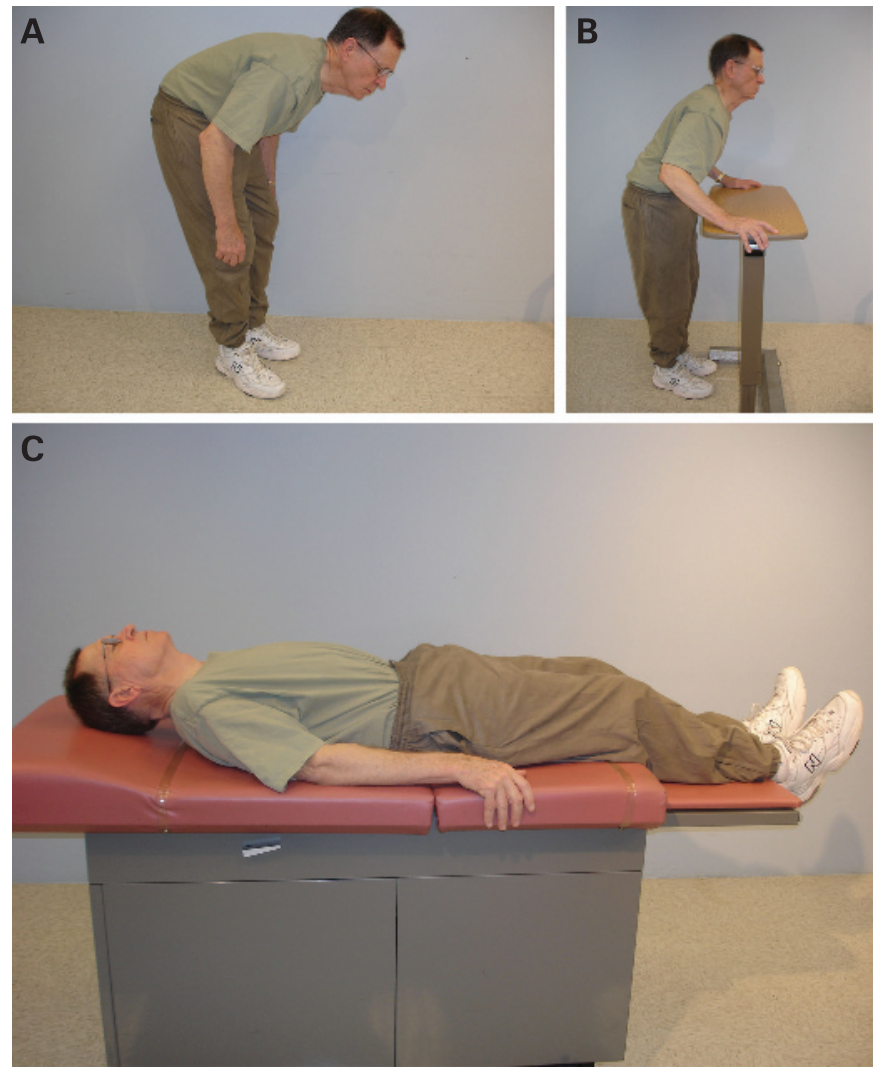

Figure 2 Camptocormia in a patient with Parkinson's disease manifested by flexion of the trunk $(A)$ which the patient can correct by pushing himself into extension posture $(B)$ or by lying in a supine position (C). Patient consent has been received to publish this figure. 
objects (eg, a walking stick, cracks in the floor), walking to music or a beat, and shifting body weight. ${ }^{6-68}$

Risk factors for the development of freezing include the presence of rigidity, bradykinesia, postural instability and longer disease duration. ${ }^{61}$ In contrast, tremor at disease onset is associated with a decreased risk of freezing. As freezing typically occurs later in the course of the disease or is not the predominant symptom, alternative diagnoses should be considered when these presentations occur. Freezing, particularly when it occurs during the $\mathrm{ON}$ period, does not usually respond to dopaminergic therapy, but patients treated with selegiline have been found to be at lower risk. ${ }^{69}$ Botulinum toxin injections, although effective for a variety of parkinsonian symptoms such as tremors, dystonia and sialorrhoea, have not been found consistently effective in the treatment of freezing. ${ }^{70}$

\section{Other motor abnormalities}

Patients with PD may exhibit a number of secondary motor symptoms that may impact on their functioning at home, at work and while driving. ${ }^{71}$ Because of a breakdown of the frontal lobe inhibitory mechanisms, some patients display a reemergence of primitive reflexes. ${ }^{72}{ }^{73}$ One study that included 41 patients with $\mathrm{PD}$ found that the primitive glabellar reflex was present in $80.5 \%$ of patients. ${ }^{74}$ This symptom was a moderately sensitive (83.3\%) indicator of a parkinsonian disorder but was not specific (47.5\%) for PD. Patients with $\mathrm{PD}$ in this study also experienced an increased frequency (34.1\%) of the palmomental reflex. This symptom was not sensitive (33.3\%) but was more specific (90\%) than the glabellar reflex. In addition, these primitive reflexes cannot differentiate among the three most common parkinsonian disorders (PD, PSP, MSA). ${ }^{74}$ Similarly, the "applause sign", initially thought to be specific for PSP, is frequently present in other parkinsonian disorders, particularly corticobasal degeneration. ${ }^{75}$ In some cases, unintended movements accompany voluntary activity in homologous muscles on the opposite side of the body. These so-called mirror movements may be observed in early asymmetric PD. ${ }^{76}$

Bulbar dysfunction manifested by dysarthria, hypophonia, dysphagia and sialorrhoea, frequently observed in patients with $\mathrm{PD}$, can be equally or even more disabling than the cardinal features. These symptoms are thought to be related to orofacial-laryngeal bradykinesia and rigidity. ${ }^{77}$ Speech disorders in patients with PD are characterised by monotonous, soft and breathy speech with variable rate and frequent word finding difficulties, referred to as "tip-of-the-tongue phenomenon." 78 Speech therapy, such as the Lee Silverman Voice Treatment, ${ }^{80}$ that emphasises efforts to improve the volume and quality of the speech, may ameliorate the symptoms of dysarthria. Dysphagia is usually caused by an inability to initiate the swallowing reflex or by a prolongation of laryngeal or oesophageal movement. Dysphagia is often subclinical, particularly in the early course of the disease. ${ }^{81} \mathrm{PD}$ related drooling may result from a decrease in swallowing. ${ }^{25}$

A number of neuro-ophthalmological abnormalities may be seen in patients with PD. These include decreased blink rate, ocular surface irritation, altered tear film, visual hallucinations, blepharospasm and decreased convergence. ${ }^{82}$ The degree of abnormality in ocular pursuit and saccades as well as antisaccades $^{83}$ is related to the degree of disease progression. ${ }^{84}$ Dopaminergic therapy generally improves these changes, but one study found no difference in smooth ocular pursuit between $\mathrm{ON}$ and OFF periods in patients with $\mathrm{PD} .{ }^{85}$ Other neuro-ophthalmological abnormalities associated with $\mathrm{PD}$ include apraxia of eyelid opening, limitation of upward gaze and oculogyric crises. ${ }^{86} 87$

Respiratory disturbances in patients with $\mathrm{PD}$ can be restrictive or obstructive. ${ }^{88}$ These complications are associated with substantial morbidity and mortality; pneumonia is an independent predictor of mortality in nursing home patients with PD. ${ }^{89}$ The obstructive pattern may be related to rigidity, cervical arthrosis or restricted range of motion in the neck, and the restrictive pattern may be related to chest wall rigidity. ${ }^{90}$ Respiration may also be compromised by levodopa related respiratory dyskinesia in patients with $\mathrm{PD} .^{91}$

\section{Non-motor features}

Non-motor symptoms are a common and under appreciated feature of PD. ${ }^{92}$ These include autonomic dysfunction, cognitive/neurobehavioral disorders, and sensory and sleep abnormalities.

\section{Autonomic dysfunction}

Autonomic failure may be the presenting feature of $\mathrm{PD}$, although it is more typically associated with MSA. Features include orthostatic hypotension, sweating dysfunction, ${ }^{93}$ sphincter dysfunction and erectile dysfunction. ${ }^{94}{ }^{95}$ A community based study found that $47 \%(42 / 89)$ of PD patients met the diagnostic criteria for orthostatic hypotension. ${ }^{96}$

\section{Cognitive and neurobehavioural abnormalities}

Neuropsychiatric disturbances can be as disabling as motor symptoms. The Sydney Multicenter Study of PD found that $84 \%$ of patients evaluated showed cognitive decline and that $48 \%$ met the diagnostic criteria for dementia after 15 years of follow-up. ${ }^{97}$ Another community based prospective study found that patients with $\mathrm{PD}$ are at almost sixfold increased risk for dementia. $^{98}$ PD related dementia is also associated with a number of other neuropsychiatric comorbidities. Among 537 such patients, depression (58\%), apathy (54\%), anxiety (49\%) and hallucinations (44\%) were frequently reported. ${ }^{99}$ In a study of 114 patients with $\mathrm{PD}, 27.6 \%$ screened positive for depression during the average 14.6 months of follow-up; $40 \%$ were neither treated with antidepressants nor referred for further psychiatric evaluation. ${ }^{100}$ In addition to cognitive and affective disorders, many patients with $\mathrm{PD}$ exhibit features of obsessive-compulsive and impulsive behaviour, such as craving (especially for sweets), ${ }^{101}$ binge eating, compulsive foraging, hypersexuality, pathological gambling, compulsive shopping and punding, characterised by intense fascination with repetitive handling, examining, sorting and arranging of objects. ${ }^{102}$ These behavioural symptoms, sometimes referred to as "hedonistic homeostatic dysregulation", have been attributed to dopamine dysregulation syndrome associated with the use of dopaminergic drugs, particularly dopamine agonists, but the mechanism of these aberrant behaviours is not well understood. ${ }^{103}$ Cognitive and behavioural dysfunction in PD is not well understood, and its discussion is beyond the scope of this article; the reader is referred to some recent reviews of this topic. ${ }^{104}$

\section{Sleep disorders}

Although sleep disturbances (eg, excessive sleepiness, sleep attacks) were once largely attributed to the pharmacological therapy for $\mathrm{PD},{ }^{105}$ some clinicians now believe that these features are an integral part of the disease. ${ }^{106}$ This is supported by the observation that rapid eye movement sleep behaviour disorder, which occurs in approximately one-third of patients 
Box 1 UK Parkinson's Disease Society Brain Bank's clinical criteria for the diagnosis of probable Parkinson's disease

Step 1

Bradykinesia

At least one of the following criteria:

Rigidity

4-6 Hz rest tremor

Postural instability not caused by primary visual, vestibular, cerebellar or proprioceptive dysfunction

Step 2

Exclude other causes of parkinsonism

Step 3

At least three of the following supportive (prospective) criteria:

Unilateral onset

Rest tremor

Progressive disorder

Persistent asymmetry primarily affecting side of onset

Excellent response $(70-100 \%)$ to levodopa

Severe levodopa induced chorea (dyskinesia)

Levodopa response for 5 years or more

Clinical course of 10 years or more

with $\mathrm{PD}$, is a substantial risk factor for the development of PD. ${ }^{107-110}$ Rapid eye movement sleep behaviour disorder, now considered a pre-parkinsonian state, is characterised by an increase in violent dream content ${ }^{110}$ accompanied by talking, yelling, swearing, grabbing, punching, kicking, jumping and other dramatic, violent and potentially injurious motor activity which may also involve the bed partner. Insomnia, particularly sleep fragmentation, is also frequent ( $>50 \%$ prevalence), but the occurrence is highly variable among patients. ${ }^{111}{ }^{112}$ The sleep abnormalities observed in patients with PD may possibly be related to a $50 \%$ loss of hypocretin (orexin) neurons. ${ }^{113}{ }^{114}$ Although excessive daytime sleepiness may contribute to fatigue, this common symptom is also seen independently of sleepiness. ${ }^{115}$

\section{Sensory abnormalities}

Sensory symptoms such as olfactory dysfunction, pain, paresthesia, akathisia, oral pain and genital pain are frequent but are often not recognised as parkinsonian symptoms. ${ }^{41}{ }^{116-121}$ One study found that olfactory dysfunction (hyposmia) may be an early marker of PD; it correlated with a 10\% increased risk for the disease 2 years later compared with other asymptomatic relatives. ${ }^{122}$ A study involving 62 pairs of twins discordant for PD found that smell identification was reduced in twins affected with PD than in those who were asymptomatic. ${ }^{123}$ It has been postulated that olfactory dysfunction is related to either neuronal loss in the corticomedial amygdala ${ }^{124}$ or to decreased dopaminergic neurons in the olfactory bulb.

\section{ASSESSMENT OF PATIENTS WITH PD Diagnostic criteria}

$\mathrm{PD}$ is diagnosed on clinical criteria; there is no definitive test for diagnosis. Historically, pathological confirmation of the hallmark Lewy body on autopsy has been considered the criterion standard for diagnosis. ${ }^{125}$ In clinical practice, diagnosis is

\section{Box 2 National Institute of Neurological Disorders and Stroke (NINDS) diagnostic criteria for Parkinson's disease (PD) ${ }^{128}$}

Group A features (characteristic of PD)

Resting tremor

Bradykinesia

Rigidity

Asymmetric onset

Group B features (suggestive of alternative diagnoses)

Features unusual early in the clinical course

Prominent postural instability in the first 3 years after symptom onset

Freezing phenomenon in the first 3 years

Hallucinations unrelated to medications in the first 3 years

Dementia preceding motor symptoms or in the first year

Supranuclear gaze palsy (other than restriction of upward gaze) or slowing of vertical saccades

Severe, symptomatic dysautonomia unrelated to medications

Documentation of condition known to produce parkinsonism and plausibly connected to the patient's symptoms (such as suitably located focal brain lesions or neuroleptic use within the past 6 months)

Criteria for definite PD

All criteria for probable Parkinson's are met and

Histopathological confirmation of the diagnosis is obtained at autopsy

Criteria for probable PD

At least three of the four features in group $A$ are present and

None of the features in group $B$ is present (note: symptom duration $\geqslant 3$ years is necessary to meet this requirement) and

Substantial and sustained response to levodopa or a dopamine agonist has been documented

Criteria for possible PD

At least two of the four features in group A are present; at least one of these is tremor or bradykinesia and

Either none of the features in group $B$ is present or symptoms have been present $\leqslant 3$ years and none of the features in group $B$ is present and

Either substantial and sustained response to levodopa or a dopamine agonist has been documented or the patient has not had an adequate trial of levodopa or a dopamine agonist 
typically based on the presence of a combination of cardinal motor features, associated and exclusionary symptoms, and response to levodopa. ${ }^{126}$ Although the diagnosis of $\mathrm{PD}$ is straightforward when patients have a classical presentation, differentiating PD from other forms of parkinsonism can be challenging early in the course of the disease, when signs and symptoms overlap with other syndromes. ${ }^{127}$

Diagnostic criteria have been developed by the UK Parkinson's Disease Society Brain Bank (box 1) and the National Institute of Neurological Disorders and Stroke (NINDS) (box 2)..$^{128}$

However, the reliability and validity of these criteria have not been clearly established. ${ }^{129}$ A study that included 100 patients who underwent biopsy after clinical diagnosis using the UK Parkinson's Disease Society Brain Bank criteria found that $76 \%$ of patients met the pathological criteria; when the diagnostic criteria were retrospectively applied, accuracy improved to $82 \% .{ }^{130}$ In a later study of the brains of patients examined by neurologists, diagnostic accuracy was considerably higher (91$92 \%) .{ }^{131}$

A study evaluating 800 patients from the DATATOP trial suggested that movement disorder specialists are skilful at diagnosing PD. ${ }^{132}$ In this study, patients were followed-up from early pretreatment stages for a mean of 7.6 years. Based on autopsy data, imaging studies, response to levodopa and atypical clinical features, only $8.1 \%$ of patients did not meet the diagnostic criteria at the final diagnosis. Although this represents an improvement in diagnostic accuracy over earlier studies, it must be noted that not all diagnoses were confirmed on pathological examination.

Misdiagnosis of PD can arise for a number of reasons. In a community based study of patients taking antiparkinsonian medication ( $n=402$ ), the most common causes of misdiagnoses were essential tremor, Alzheimer's disease and vascular parkinsonism. ${ }^{127}{ }^{133}$ More than $25 \%$ of patients in this study did not respond to antiparkinsonian medication. In addition, many of the prominent features of PD (eg, rigidity, gait disturbance, bradykinesia) may also occur as a result of normal aging or from comorbid and multifactorial medical conditions (eg, diabetes, cancer). ${ }^{134} 135$

\section{Differential diagnosis}

Parkinsonian disorders can be classified as four types: primary (idiopathic) parkinsonism, secondary (acquired, symptomatic) parkinsonism, heredodegenerative parkinsonism and multiple system degeneration (parkinsonism plus syndromes). Several features, such as tremor, early gait abnormality (eg, freezing), postural instability, pyramidal tract findings and response to levodopa, can be used to differentiate PD from other parkinsonian disorders. Although differences in the density of postsynaptic dopamine receptors in patients with PD or other atypical parkinsonian disorders have been used to explain the poor response to levodopa therapy in the latter group, this may not be the only explanation. Recent positron emission tomography imaging studies have shown relative preservation of dopamine receptors in PSP, ${ }^{136}$ suggesting downstream changes as a possible mechanism for the lack of response. Furthermore, patients with MSA often have excellent initial responses but frequently develop levodopa related orofacial dyskinesias and lose antiparkinsonian efficacy. Although improvement with levodopa is suggestive of $\mathrm{PD}$, it does not definitively differentiate PD from other parkinsonian disorders. ${ }^{137}$ One study found that only $77 \%$ of patients with pathologically proven PD had a "good" or "excellent" initial response to levodopa. ${ }^{36}$ Subcutaneous injection of apomorphine has been used to differentiate between PD and other parkinsonian disorders; however, this test is not superior to levodopa therapy and contributes little to diagnostic evaluation. ${ }^{138}$

Neuroimaging techniques may also be useful for differentiating PD from other parkinsonian disorders. ${ }^{139}$ Potential imaging studies include high field strength $(1.5 \mathrm{~T})$ heavily $\mathrm{T}_{2}$ weighted $\mathrm{MRI},{ }^{139}\left[{ }^{18} \mathrm{~F}\right]$-fluorodopa positron emission tomography, ${ }^{139}\left[{ }^{11} \mathrm{C}\right]-$ raclopride imaging of dopamine $\mathrm{D} 2$ receptors ${ }^{140}$ and single photon emission computed tomography of striatal dopamine reuptake sites. ${ }^{141}$ One study suggested that brain parenchyma sonography may be highly specific for differentiating between $\mathrm{PD}$ and atypical parkinsonism ${ }^{142}$; however, it also showed abnormal hyperechogenicity not only in PD but in essential tremor. ${ }^{143}$ Although these neuroimaging techniques are promising, further refinement in resolution and improvement in sensitivity are needed before their diagnostic potential is fully realised.

\section{CONCLUSIONS}

$\mathrm{PD}$ is a progressive neurodegenerative disorder manifested by a broad spectrum of motor and non-motor features. The natural progression of $\mathrm{PD}$ is variable but is usually more rapid in patients with late onset and with the PIGD form of PD. In a comprehensive review of the literature, the standardised mortality ratio has been reported to range between 1 and 3.4. ${ }^{144}$ Because there are no definitive diagnostic tests for it, clinicians require thorough knowledge of the clinical manifestations of PD to aid them in differentiating it from related disorders. Future research may uncover disease specific biomarkers allowing for its differentiation from other neurodegenerative disorders. Not only will such testing be useful for diagnosing the disease in affected persons, it will be useful for identifying family members or populations at risk, thus providing an opportunity to initiate neuroprotective therapy at an asymptomatic stage.

Acknowledgements: I would like to thank the National Parkinson Foundation for its support of our NPF Center of Excellence and Susan Quiñones, PhD for editorial assistance.

Competing interests: None

Patient consent: Patient consent has been received to publish the figures in this paper.

\section{REFERENCES}

1. Parkinson J. An essay on the shaking palsy. J Neuropsychiatry Clin Neurosci 2002;14:223-36.

2. Kempster PA, Hurwitz B, Lees AJ. A new look at James Parkinson's essay on the shaking palsy. Neurology 2007;69:482-5.

3. Bjorklund A, Dunnett SB. Dopamine neuron systems in the brain: an update. Trends Neurosci 2007;30:194-202.

4. Hornykiewicz $\mathbf{0}$. The discovery of dopamine deficiency in the parkinsonian brain J Neural Transm 2006:70:9-15.

5. Birkmayer W, Hornykiewicz 0. The L-3,4-dioxyphenylalanine (DOPA)-effect in Parkinson-akinesia. Wien Klin Wochenschr 1961;73:787-8.

6. Birkmayer $\mathbf{W}$, Hornykiewicz 0 . The effect of L-3, 4-dihydroxyphenylalanine (LDOPA) on akinesia in parkinsonism. Parkinsonism Relat Disord 1998;4:59-60.

7. Cotzias GC, Papavasiliou PS, Gellene R. Modification of parkinsonism: chronic treatment with L-DOPA. N Engl J Med 1969;280:337-45.

8. McNaught KSP, Jenner P, Olanow CW. Protein mishandling: Role of the ubiquitin proteasome system in the pathogenesis of Parkinson's disease. In: Jankovic J, Tolosa E, eds. Parkinson's disease and movement disorders. Philadelphia: Lippincott Williams and Wilkins, 2007:33-49.

9. Pan T, Kondo S, Le W, et al. The role of autophagy-lysosome pathway in neurodegeneration associated with Parkinson's disease. Brain 2008 (Epub ahead of print).

10. Jankovic J, Tolosa E. Parkinson's disease and movement disorders. Philadelphia: Lippincott Williams and Wilkins, 2007.

11. Fahn S, Jankovic J. Principles and practice of movement disorders. Philadelphia: Elsevier, 2007. 
12. Jankovic J. Pathophysiology and assessment of parkinsonian symptoms and signs. In: Pahwa R, Lyons K, Koller WC, eds. Handbook of Parkinson's disease. New York: Taylor and Francis Group, LLC, 2007:79-104.

13. Ramaker C, Marinus J, Stiggelbout AM, et al. Systematic evaluation of rating scales for impairment and disability in Parkinson's disease. Mov Disord 2002;17:867-76.

14. Ebersbach G, Baas H, Csoti l, et al. Scales in Parkinson's disease. J Neurol 2006;253:iv32-5.

15. Goetz CG, Fahn S, Martinez-Martin P, et al. Movement Disorder Society-sponsored revision of the Unified Parkinson's Disease Rating Scale (MDS-UPDRS): process, format, and clinimetric testing plan. Mov Disord 2007:22:41-7.

16. Jankovic J, Kapadia AS. Functional decline in Parkinson disease. Arch Neuro 2001;58:1611-5.

17. Lang AE. The progression of Parkinson disease: a hypothesis. Neurology 2007;68:948-52.

18. Post B, Merkus MP, Haan RJ, et al. Prognostic factors for the progression of Parkinson's disease: A systematic review. Mov Disord 2007:22:1839-51.

19. Jankovic J, Stacy M. Medical management of levodopa-associated motor complications in patients with Parkinson's disease. CNS Drugs 2007:21:677-92.

20. Schrag A, Dodel R, Spottke A, et al. Rate of clinical progression in Parkinson's disease. A prospective study. Mov Disord 2007;22:938-45.

21. Schrag A, Barone P, Brown RG, et al. Depression rating scales in Parkinson's disease: critique and recommendations. Mov Disord 2007;22:1077-92.

22. Berardelli A, Rothwell JC, Thompson PD, et al. Pathophysiology of bradykinesia in Parkinson's disease. Brain 2001;124:2131-46.

23. Cooper JA, Sagar HJ, Tidswell $P$, et al. Slowed central processing in simple and go/no-go reaction time tasks in Parkinson's disease. Brain 1994;117:517-29.

24. Giovannoni G, van Schalkwyk J, Fritz VU, et al. Bradykinesia akinesia incoordination test (BRAIN TEST): an objective computerised assessment of upper limb motor function. J Neurol Neurosurg Psychiatry 1999;67:624-9.

25. Bagheri H, Damase-Michel C, Lapeyre-Mestre M, et al. A study of salivary secretion in Parkinson's disease. Clin Neuropharmacol 1999;22:213-15.

26. Vingerhoets FJG, Schulzer M, Calne DB, et al. Which clinical sign of Parkinson's disease best reflects the nigrostriatal lesion? Ann Neurol 1997:41:58-64.

27. Ross GW, Petrovitch $\mathrm{H}$, Abbott RD, et al. Parkinsonian signs and substantia nigra neuron density in decendents elders without PD. Ann Neurol 2004:56:532-9.

28. Lozza C, Marie RM, Baron JC. The metabolic substrates of bradykinesia and tremor in uncomplicated Parkinson's disease. Neuroimage 2002;17:688-99.

29. Parr-Brownlie LC, Hyland Bl. Bradykinesia induced by dopamine $\mathrm{D}_{2}$ receptor blockade is associated with reduced motor cortex activity in the rat. J Neurosci 2005:25:5700-9.

30. Turner RS, Grafton ST, Mclntosh AR, et al. The functional anatomy of parkinsonian bradykinesia. Neuroimage 2003;19:163-79.

31. Hallett M, Khoshbin S. A physiological mechanism of bradykinesia. Brain 1980; 103:301-14

32. Shulman LM, Singer C, Bean JA, et al. Internal tremor in patients with Parkinson's disease. Mov Disord 1996;11:3-7

33. Shahed J, Jankovic J. Exploring the relationship between essential tremor and Parkinson's disease. Parkinsonism Relat Disord 2007:13:67-76.

34. Jankovic J, Schwartz KS, Ondo W. Re-emergent tremor of Parkinson's disease. J Neurol Neurosurg Psychiatry 1999;67:646-50.

35. Jankovic J. Essential tremor: a heterogenous disorder. Mov Disord 2002;17:63844.

36. Hughes AJ, Daniel SE, Blankson S, et al. A clinicopathologic study of 100 cases of Parkinson's disease. Arch Neurol 1993;50:140-8.

37. Martin WE, Loewenson RB, Resch JA, et al. Parkinson's disease: clinical analysis of 100 patients. Neurology 1973;23:783-90.

38. Rajput AH, Rozdilsky B, Rajput A. Accuracy of clinical diagnosis in parkinsonism: a prospective study. Can J Neurol Sci 1991;18:275-8.

39. Broussolle $\mathbf{E}$, Krack $P$, Thobois $S$, et al. Contribution of Jules Froment to the study of parkinsonian rigidity. Mov Disord 2007:22:909-14.

40. Riley D, Lang AE, Blair RD, et al. Frozen shoulder and other shoulder disturbances in Parkinson's disease. J Neurol Neurosurg Psychiatry 1989:52:63-6.

41. Stamey WP, Jankovic J. Shoulder pain in Parkinson's disease. Mov Disord 2007;22:S247-8.

42. de Lau LML, Koudstaal PJ, Hofman A, et al. Subjective complaints precede Parkinson disease: the Rotterdam study. Arch Neurol 2006;63:362-5.

43. Ashour R, Tintner R, Jankovic J. Striatal deformities of the hand and foot in Parkinson's disease. Lancet Neurol 2005:4:423-31.

44. Ashour R, Jankovic J. Joint and skeletal deformities in Parkinson's disease, multiple system atrophy, and progressive supranuclear palsy. Mov Disord 2006;21:1856-63.

45. Winkler AS, Reuter I, Harwood G, et al. The frequency and significance of 'striatal toe' in parkinsonism. Parkinsonism Relat Disord 2002:9:97-101.

46. Askmark H, Eeg-Olofsson KE, Johansson A, et al. Parkinsonism and neck extensor myopathy: a new syndrome or coincidental findings? Arch Neurol 2001;58:232-7.

47. Djaldetti R, Melamed E. Camptocormia in Parkinson's disease: new insights. J Neurol Neurosurg Psychiatry 2006;77:1205

48. Azher SN, Jankovic J. Camptocormia: pathogenesis, classification, and response to therapy. Neurology 2005;65:355-9.

49. Bloch F, Houeto JL, Tezenas du MS, et al. Parkinson's disease with camptocormia. J Neurol Neurosurg Psychiatry 2006:77:1223-8.
50. Djaldetti R, Mosberg-Galili R, Sroka H, et al. Camptocormia (bent spine) in patients with Parkinson's disease - characterization and possible pathogenesis of an unusual phenomenon. Mov Disord 1999;14:443-7.

51. Villarejo A, Camacho A, Garcia-Ramos R, et al. Cholinergic-dopaminergic imbalance in Pisa syndrome. Clin Neuropharmacol 2003;26:119-21.

52. Williams DR, Watt HC, Lees AJ. Predictors of falls and fractures in bradykinetic rigid syndromes: a retrospective study. J Neurol Neurosurg Psychiatry 2006;77:468-73

53. Wenning GK, Ebersbach G, Verny M, et al. Progression of falls in postmortemconfirmed parkinsonian disorders. Mov Disord 1999;14:947-50.

54. Bloem BR. Postural instability in Parkinson's disease. Clin Neurol Neurosurg 1992;94:S41-5

55. Bronte-Stewart HM, Minn AY, Rodrigues K, et al. Postural instability in idiopathic Parkinson's disease: the role of medication and unilateral pallidotomy. Brain 2002;125:2100-14.

56. Adkin AL, Frank JS, Jog MS. Fear of falling and postural control in Parkinson's disease. Mov Disord 2003;18:496-502.

57. Koller WC, Glatt S, Vetere-Overfield B, et al. Falls and Parkinson's disease. Clin Neuropharmacol 1989:12:98-105.

58. Roberts-Warrior D, Overby A, Jankovic J, et al. Postural control in Parkinson's disease after unilateral posteroventral pallidotomy. Brain 2000;123:2141-9.

59. Maurer C, Mergner T, Xie J, et al. Effect of chronic bilateral subthalamic nucleus (STN) stimulation on postural control in Parkinson's disease. Brain 2003;126:114663.

60. Stefani A, Lozano AM, Peppe A, et al. Bilateral deep brain stimulation of the pedunculopontine and subthalamic nuclei in severe Parkinson's disease. Brain 2007; 130:1596-607.

61. Giladi N, McDermott MP, Fahn $\mathrm{S}$, et al. Freezing of gait in PD: prospective assessment in the DATATOP cohort. Neurology 2001:56:1712-21.

62. Bloem BR, Hausdorff JM, Visser JE, et al. Falls and freezing of gait in Parkinson's disease: a review of two interconnected, episodic phenomena. Mov Disord 2004;19:871-84.

63. Macht M, Kaussner $Y$, Moller JC, et al. Predictors of freezing in Parkinson's disease: a survey of 6,620 patients. Mov Disord 2007:22:953-6.

64. Boghen D. Apraxia of lid opening: a review. Neurology 1997;48:1491-4.

65. Schaafsma JD, Balash Y, Gurevich T, et al. Characterization of freezing of gait subtypes and the response of each to levodopa in Parkinson's disease. Eur J Neurol 2003;10:391-8.

66. Dietz MA, Goetz CG, Stebbins GT. Evaluation of a modified inverted walking stick as a treatment for parkinsonian freezing episodes. Mov Disord 1990;5:243-7.

67. Arias $\mathbf{P}$, Cudeiro J. Effects of rhythmic sensory stimulation (auditory, visual) on gait in Parkinson's disease patients. Exp Brain Res 2008 (Epub ahead of print 23 Jan).

68. Marchese R, Diverio M, Zucchi F, et al. The role of sensory cues in the rehabilitation of parkinsonian patients: a comparison of two physical therapy protocols. Mov Disord 2000;15:879-83.

69. Giladi N, Kao R, Fahn S. Freezing phenomenon in patients with parkinsonian syndromes. Mov Disord 1997:12:302-5.

70. Sheffield JK, Jankovic J. Botulinum toxin in the treatment of tremors, dystonias, sialorrhea and other symptoms associated with Parkinson's disease. Exp Rev Neurother 2007;7:637-47.

71. Singh R, Pentland B, Hunter J, et al. Parkinson's disease and driving ability. J Neurol Neurosurg Psychiatry 2007;78:363-6.

72. Thomas RJ. Blinking and the release reflexes: are they clinically useful? J Am Geriatr Soc 1994:42:609-13.

73. Vreeling FW, Jolles J, Verhey FRJ, et al. Primitive reflexes in healthy, adult volunteers and neurological patients: methodological issues. J Neurol 1993;240:495-504.

74. Brodsky H, Dat Vuong K, Thomas $\mathrm{M}$, et al. Glabellar and palmomental reflexes in Parkinsonian disorders. Neurology 2004;63:1096-8.

75. Wu J, Sitburana 0, Jankovic J. The specificity and sensitivity of "applause sign" in differentiating PSP and other parkinsonian syndromes. Mov Disord 2007:22:S254-5.

76. Li JY, Espay AJ, Gunraj CA, et al. Interhemispheric and ipsilateral connections in Parkinson's disease: relation to mirror movements. Mov Disord 2007:22:813-21.

77. Hunker CJ, Abbs JH, Barlow SM. The relationship between parkinsonian rigidity and hypokinesia in the orofacial system: a quantitative analysis. Neurology 1982;32:749-54.

78. Matison R, Mayeux R, Rosen J, et al. "Tip-of-the-tongue" phenomenon in Parkinson disease. Neurology 1982:32:567-70.

79. Critchley EMR. Speech disorders of Parkinsonism: a review. J Neurol Neurosurg Psychiatry 1981:44:751-8.

80. Sapir S, Spielman JL, Ramig LO, et al. Effects of intensive voice treatment (the Lee Silverman Voice Treatment [LSVT]) on vowel articulation in dysarthric individuals with idiopathic Parkinson disease: acoustic and perceptual findings. J Speech Lang Hear Res 2007;50:899-912.

81. Potulska A, Friedman A, Krolicki L, et al. Swallowing disorders in Parkinson's disease. Parkinsonism Relat Disord 2003:9:349-53.

82. Biousse V, Skibell BC, Watts RL, et al. Ophthalmologic features of Parkinson's disease. Neurology 2004:62:177-80.

83. Hood AJ, Amador SC, Cain AE, et al. Levodopa slows prosaccades and improves antisaccades: an eye movement study in Parkinson's disease. J Neurol Neurosurg Psychiatry 2007:78:565-70. 
84. Rascol 0, Clanet M, Montastruc JL, et al. Abnormal ocular movements in Parkinson's disease: evidence for involvement of dopaminergic systems. Brain 1989;112:1193-214

85. Sharpe JA, Fletcher WA, Lang AE, et al. Smooth pursuit during dose-related on-off fluctuations in Parkinson's disease. Neurology 1987;37:1389-92.

86. Zadikoff C, Lang AE. Apraxia in movement disorders. Brain 2005;128:1480-97.

87. Linazasoro G, Van Blercom N, Lasa A. Levodopa-induced ocular dyskinesias in Parkinson's disease. Mov Disord 2002;17:186-7.

88. Sabate M, Gonzalez I, Ruperez F, et al. Obstructive and restrictive pulmonary dysfunctions in Parkinson's disease. J Neurol Sci 1996:138:114-19.

89. Fernandez $\mathbf{H H}$, Lapane KL. Predictors of mortality among nursing home residents with a diagnosis of Parkinson's disease. Med Sci Monit 2002;8:CR241-6.

90. Shill H, Stacy M. Respiratory function in Parkinson's disease. Clin Neurosci 1998;5:131-5

91. Jankovic J, Nour F. Respiratory dyskinesia in Parkinson's disease. Neurology 1986;36:303-4.

92. Zesiewicz TA, Sullivan KL, Hauser RA. Nonmotor symptoms of Parkinson's disease. Exp Rev Neurother 2006;6:1811-22.

93. Pursiainen V, Haapaniemi TH, Korpelainen JT, et al. Sweating in Parkinsonian patients with wearing-off. Mov Disord 2007;22:828-32.

94. Senard JM, Rai S, Lapeyre-Mestre M, et al. Prevalence of orthostatic hypotension in Parkinson's disease. J Neurol Neurosurg Psychiatry 1997;63:584-9.

95. Swinn L, Schrag A, Viswanathan R, et al. Sweating dysfunction in Parkinson's disease. Mov Disord 2003;18:1459-63.

96. Allcock LM, Ullyart K, Kenny RA, et al. Frequency of orthostatic hypotension in a community based cohort of patients with Parkinson's disease. J Neurol Neurosurg Psychiatry 2004;75:1470-1.

97. Hely MA, Morris JGL, Reid WGJ, et al. Sydney Multicenter Study of Parkinson's disease: non-L-dopa-responsive problems dominate at 15 years. Mov Disord 2005;20:190-9.

98. Aarsland D, Andersen K, Larsen JP, et al. Risk of dementia in Parkinson's disease: a community-based, prospective study. Neurology 2001:56:730-6.

99. Aarsland D, Bronnick K, Ehrt U, et al. Neuropsychiatric symptoms in patients with Parkinson's disease and dementia: frequency, profile and associated care giver stress. J Neurol Neurosurg Psychiatry 2007;78:36-42.

100. Ravina B, Camicioli R, Como PG, et al. The impact of depressive symptoms in early Parkinson disease. Neurology 2007:69:342-7.

101. Palmiter RD. Is dopamine a physiologically relevant mediator of feeding behavior? Trends Neurosci 2007:30:375-81.

102. Miyasaki JM, Al HK, Lang AE, et al. Punding prevalence in Parkinson's disease. Mov Disord 2007;22:1179-81.

103. Weintraub D, Siderowf AD, Potenza MN, et al. Association of dopamine agonist use with impulse control disorders in Parkinson disease. Arch Neurol 2006:63:969_ 73.

104. Sawamoto N, Honda M, Hanakawa T, et al. Cognitive slowing in Parkinson disease is accompanied by hypofunctioning of the striatum. Neurology 2007;68:1062-8.

105. Ondo WG, Dat Vuong K, Khan H, et al. Daytime sleepiness and other sleep disorders in Parkinson's disease. Neurology 2001:57:1392-6.

106. Gjerstad MD, Alves G, Wentzel-Larsen T, et al. Excessive daytime sleepiness in Parkinson disease: is it the drugs or the disease? Neurology 2006;67:853-8.

107. Schenck CH, Bundlie SR, Mahowald MW. Delayed emergence of a parkinsonian disorder in $38 \%$ of 29 older men initially diagnosed with idiopathic rapid eye movement sleep behavior disorder. Neurology 1996;46:388-93

108. Plazzi G, Corsini R, Provini F, et al. REM sleep behavior disorders in multiple system atrophy. Neurology 1997:48:1094-7.

109. Gagnon J-F, Postuma RB, Mazza S, et al. Rapid-eye-movement sleep behaviour disorder and neurodegenerative diseases. Lancet Neurol 2006;5:424-32.

110. Borek LL, Kohn R, Friedman JH. Phenomenology of dreams in Parkinson's disease Mov Disord 2007:22:198-202.

111. Gjerstad MD, Wentzel-Larsen T, Aarsland D, et al. Insomnia in Parkinson's disease: frequency and progression over time. J Neurol Neurosurg Psychiatry 2007;78:476-

112. Boeve BF, Silber MH, Saper CB, et al. Pathophysiology of REM sleep behaviour disorder and relevance to neurodegenerative disease. Brain 2007;130(Pt 11):2770_ 88.

113. Fronczek R, Overeem S, Lee SY, et al. Hypocretin (orexin) loss in Parkinson's disease. Brain 2007:130:1577-85.

114. Thannickal TC, Lai YY, Siegel JM. Hypocretin (orexin) cell loss in Parkinson's disease. Brain 2007;130:1586-95.
115. Friedman JH, Brown RG, Comella C, et al. Fatigue in Parkinson's disease: a review. Mov Disord 2007;22:297-308.

116. Stern MB, Doty RL, Dotti M, et al. Olfactory function in Parkinson's disease subtypes. Neurology 1994:44:266-8.

117. Lee PH, Yeo SH, Kim HJ, et al. Correlation between cardiac ${ }^{123} \mathrm{I}-\mathrm{MIBG}$ and odor identification in patients with Parkinson's disease and multiple system atrophy. Mov Disord 2006:21:1975-7.

118. Comella CL, Goetz CG. Akathisia in Parkinson's disease. Mov Disord 1994;9:545-9

119. Ford B, Louis ED, Greene P, et al. Oral and genital pain syndromes in Parkinson's disease. Mov Disord 1996;11:421-6.

120. Djaldetti R, Shifrin A, Rogowski Z, et al. Quantitative measurement of pain sensation in patients with Parkinson disease. Neurology 2004:62:2171-5.

121. Tinazzi M, Del Vesco C, Fincati E, et al. Pain and motor complications in Parkinson's disease. J Neurol Neurosurg Psychiatry 2006:77:822-5.

122. Ponsen MM, Stoffers D, Booij J, et al. Idiopathic hyposmia as a preclinical sign of Parkinson's disease. Ann Neurol 2004;56:173-81.

123. Marras C, Goldman S, Smith A, et al. Smell identification ability in twin pairs discordant for Parkinson's disease. Mov Disord 2005;20:687-93.

124. Harding AJ, Stimson E, Henderson JM, et al. Clinical correlates of selective pathology in the amygdala of patients with Parkinson's disease. Brain 2002; 125:2431-45.

125. Gibb WR, Lees AJ. The relevance of the Lewy body to the pathogenesis of idiopathic Parkinson's disease. J Neurol Neurosurg Psychiatry 1988;51:745-52.

126. Rao G, Fisch L, Srinivasan S, et al. Does this patient have Parkinson disease? JAMA 2003:289:347-53

127. Tolosa $\mathbf{E}$, Wenning G, Poewe W. The diagnosis of Parkinson's disease. Lancet Neurol 2006:5:75-86.

128. Gelb DJ, Oliver E, Gilman S. Diagnostic criteria for Parkinson disease. Arch Neurol 1999:56:33-9.

129. de Rijk MC, Rocca WA, Anderson DW, et al. A population perspective on diagnostic criteria for Parkinson's disease. Neurology 1997;48:1277-81.

130. Hughes AJ, Ben-Shlomo Y, Daniel SE, et al. What features improve the accuracy of clinical diagnosis in Parkinson's disease: a clinicopathologic study. Neurology 1992:42:1142-6.

131. Hughes AJ, Daniel SE, Lees AJ. Improved accuracy of clinical diagnosis of Lewy body Parkinson's disease. Neurology 2001:57:1497-9.

132. Jankovic J, Rajput AH, McDermott MP, et al. The evolution of diagnosis in early Parkinson disease. Arch Neurol 2000:57:369-72.

133. Meara J, Bhowmick BK, Hobson P. Accuracy of diagnosis in patients with presumed Parkinson's disease. Age Ageing 1999;28:99-102.

134. Arvanitakis Z, Wilson RS, Schneider JA, et al. Diabetes mellitus and progression of rigidity and gait disturbance in older persons. Neurology 2004;63:996-1001.

135. Inzelberg R, Jankovic J. Are Parkinson disease patients protected from some but not all cancers? Neurology 2007;69:1542-50.

136. Warren NM, Piggott MA, Greally E, et al. Basal ganglia cholinergic and dopaminergic function in progressive supranuclear palsy. Mov Disord 2007;22:1594-1600

137. Parati EA, Fetoni V, Geminiani GC, et al. Response to L-DOPA in multiple system atrophy. Clin Neuropharmacol 1993;16:139-44.

138. Clarke CE, Davies P. Systematic review of acute levodopa and apomorphine challenge tests in the diagnosis of idiopathic Parkinson's disease. J Neurol Neurosurg Psychiatry 2000;69:590-4.

139. Piccini P, Brooks DJ. New developments of brain imaging for Parkinson's disease and related disorders. Mov Disord 2006;21:2035-41.

140. Brooks DJ, Ibanez V, Sawle GV, et al. Striatal $D_{2}$ receptor status in patients with Parkinson's disease, striatonigral degeneration, and progressive supranuclear palsy, measured with ${ }^{11} \mathrm{C}$-raclopride and positron emission tomography. Ann Neurol 1992;31:184-92.

141. Marek KL, Seibyl JP, Zoghbi SS, et al. [ $\left.{ }^{123} \mid\right]$ beta-CIT/SPECT imaging demonstrates bilateral loss of dopamine transporters in hemi-Parkinson's disease. Neurology 1996:46:231-7.

142. Walter U, Niehaus L, Probst T, et al. Brain parenchyma sonography discriminates Parkinson's disease and atypical parkinsonian syndromes. Neurology 2003:60:74-7.

143. Stockner H, Sojer M, KS K, et al. Midbrain sonography in patients with essentia tremor. Mov Disord 2007;22:414-7.

144. Ishihara LS, Cheesbrough A, Brayne C, et al. Estimated life expectancy of Parkinson's patients compared with the UK population. J Neurol Neurosurg Psychiatry 2007;78:1304-9. 